\title{
Analysis of Immune Response in Yellowtail upon Vaccination with a Bivalent Vaccine of Vibrio anguillarum and Lactococcus garvieae
}

\author{
Nao Nakajima ${ }^{1,3 *}$, Mayumi Kijima ${ }^{1}$, Michiko Kawanishi ${ }^{1}$, Goushi Katou ${ }^{2}$, Kunihiko Futami ${ }^{3}$, \\ Takayuki Katagiri ${ }^{3}$, Makoto Endo ${ }^{3}$ and Masashi Maita ${ }^{3}$ \\ ${ }^{1}$ National Veterinary Assay Laboratory, Ministry of Agriculture, Forestry and Fisheries, \\ Tokyo 185-8511, Japan \\ ${ }^{2}$ Laboratory of Genome Science, Tokyo University of Marine Science and \\ Technology, Tokyo 108-8477, Japan \\ ${ }^{3}$ Laboratory of Fish Health Management, Tokyo University of Marine \\ Science and Technology, Tokyo 108-8477, Japan
}

(Received October 4, 2011)

\begin{abstract}
We inoculated yellowtail Seriola quinqueradiata with a commercial bivalent vaccine containing inactivated Vibrio anguillarum and Lactococcus garvieae to better understand the immunological responses to the vaccination. Serum samples were collected from vaccinated and control (PBS-injected) fish at $1,3,5,7,10$, and 14 days post-vaccination (dpv). Compared to the controls, the serum from the vaccinated fish inhibited the proliferation of $V$. anguillarum from $7 \mathrm{dpv}$. However, vaccination had no effect on $L$. garvieae proliferation. The antibody titer against $V$. anguillarum obviously increased from 7 dpv, but no such increase was detected for L. garvieae. We confirmed that the protection conferred by the $V$. anguillarum vaccine was a result of the antibodies against the pathogen. However, humoral factors related to protection were not observed for $L$. garvieae. The expression of immune-related genes in the head kidney was profiled by microarray analysis. Twenty-two immune-related genes were up-regulated during the experimental period. Up-regulation of cellular immune-related genes, such as tumor necrosis factor, CC chemokine, and macrophage colony-stimulating factor receptor, was mostly observed from 1 to $3 \mathrm{dpv}$, whereas that of humoral immune-related genes was observed from 3 to $14 \mathrm{dpv}$. Notably, immunoglobulin-related genes showed continuous up-regulation during the 2-week experimental period.
\end{abstract}

Key words: Seriola quinqueradiata, Yellowtail, Vaccine, Immune response, Gene expression, Vibrio anguillarum, Lactococcus garvieae

Vaccination is an effective tool for the control of infectious diseases in farmed fish. The first vaccine approved for use against vibriosis in ayu was developed in 1988 and following that, a number of other vaccines have been developed. Currently, 14 vaccines are licensed in Japan.

For a vaccine to be manufactured and sold, pharmaceutical affairs law requires licensing of the vaccine by the Ministry of Agriculture, Forestry and Fisheries. The efficacy of fish vaccine is normally evaluated by a challenge test, the exception of which is the Vibrio vaccine, which was evaluated by the agglutination antibody titer test.

The challenge test requires a large number of fish and raises several ethical issues. From the perspec-

\footnotetext{
* Corresponding author

E-mail: aoki@nval.maff.go.jp
}

tive of animal welfare, the number of animals tested and their suffering must be minimized, but it is difficult to do so as long as the challenge test is used as the official licensing examination. The second issue is the facility used. A number of vaccines have been developed recently and a large number of experimental fish are needed to test each product. Therefore, larger spaces are required for stocking experimental fish. This implies a considerable cost increase. One final complication is reproducibility. The challenge test does not always yield reproducible results due to fish size differences and bacterial pathogenicity. Solving these problems requires the development of an alternative to the challenge test.

To develop an alternative to the challenge test, it is necessary to find a suitable parameter for vaccine evaluation. To this end, a large-scale screening of immune response in yellowtail was conducted in this 
study. Yellowtail stimulated with a bivalent vaccine were used to measure antibacterial activity in serum and skin mucus, determine antibody titer, and profile gene expression by microarray analysis.

In Japan, Seriola fish, including Seriola quinqueradiata, Seriola dumerili, and Seriola lalandi, is one of the most important farmed fish. At Vibrio vaccine co-relationship between agglutination antibody titer and vaccine efficacy is examined on approval process, and there are reports of the antibody response of Seriola dumerili to V. anguillarum (Zaccone and Mancuso, 2008) and Red Sea Bream Iridovirus (Kwon et al., 2010). The immune response of yellowtail to different phenotypes of $L$. garvieae (lida et al., 1982; Yoshida et al., 1996, 1997; Hirono et al., 1999; Ooyama et al., 1999, 2002) was studied and vaccination was evaluated (lida et al., 1982). However, the underlying mechanism of immune induction following vaccination in Seriola fish is still not well understood.

Antibody titer is the most popular parameter for the determination of vaccine efficacy in mammals. If antibody titer could be used in the licensing of fish vaccines, many of the problems associated with the challenge test would be solved. Except Vibrio vaccine, there is little information on the antibody response of Seriola fish to vaccination, although the vaccines have a strong protective effect. In other fish, several studies of antibody reaction have been conducted. In Atlantic cod with vibriosis vaccine and the relationship between vaccine efficacy and antibody response has been thoroughly studied but not completely understood (Pilström and Petersson, 1991; Bengtén et al., 1994; Stenvik et al., 2000; Caipang et al., 2008, 2009). Espelide et al. (1991) suggested that the efficacy of vibriosis vaccine developed for Atlantic cod is not related to the antibody response of the fish. Atlantic salmon is able to produce a strong antibody response to both Vibrio salmonicida and V. anguillarum (Steine et al., 2001). Antibody response to lipopolysaccharide (LPS) has been reported in other fish species, including rainbow trout (Hasting and Ellis, 1990), spotted wolfish (Grøntvedt and Sigrun, 2004), and halibut (Schrøder et al., 1992; Ingilæ et al., 2000).

Generally, mucus covering skin surface acts as the first barrier against infection (Ellis, 2001). The important role of mucus in defense against infections is well known and has been studied in several fish species (Hjelmeland et al., 1983; Rombout et al., 1993; Fasta et al., 2002). To compare the antibacterial activities of mucus and serum, a bacterial proliferation inhibition test was performed.

Microarray analysis is an efficient method for largescale gene expression. It is suitable to search which genes play an important role in vaccine-induced immunity. In this study, we used DNA microarray to examine gene expression profile of yellowtail after vacci- nation, to elucidate their immune response at the molecular level. In yellowtail, vaccines against $V$. anguillarum and L. garvieae are the most common. Considering actual usage and history, a bivalent vaccine consisting of inactivated $V$. anguillarum and $L$. garvieae was used in this study.

\section{Materials and Methods}

Fish

A total of 48 healthy, artificially hatched yellowtail with weights ranging from 171 to $431 \mathrm{~g}$ were used. Six fish each were stocked in $200 \mathrm{~L}$ circular tanks at the National Veterinary Assay Laboratory, Japan. Water temperature was kept at $25^{\circ} \mathrm{C}$ and the salinity of rearing seawater was checked every day. Fish were fed standard commercial diet for yellowtail throughout the experiment. Handling was done according to the National Veterinary Assay Laboratory's animal management guidelines.

\section{Vaccine and vaccination}

Commercial inactivated bivalent vaccine containing the antigens of $V$. anguillarum and L. garvieae (Kyoritu) was stored at $4^{\circ} \mathrm{C}$ and injected according to the instructions on the package leaflet. The commercial vaccine has passed the licensing examination by the National Veterinary Assay Laboratory. Vaccine quality was confirmed by National Veterinary Assay Protocol: Antibody titer against $V$. anguillarum should be $\leqq 16$ in vaccinated fish serum, whereas in control fish serum, it should be $\leqq 2$. Mortality resulting from the challenge with $L$. garvieae must show a significant difference $(p<0.05)$ between vaccinated fish and control (phosphate buffered saline (PBS)-injected) fish. Thirty fish were injected intraperitoneally with $0.1 \mathrm{~mL}$ of vaccine. Eighteen fish were treated with the same amount of sterile PBS as control.

\section{Blood and skin mucus sampling}

Sampling was conducted at 1, 3, 5, 7, 10, and 14 days post vaccination (dpv). Five fish from the vaccinated group and three fish from the control group were anesthetized with FA-100 (Tanabe Seiyaku) and blood was rapidly collected by cardiac puncture using nonheparinized syringes. Blood samples were incubated at room temperature $\left(18\right.$ to $23^{\circ} \mathrm{C}$ ) for $1 \mathrm{~h}$ and then stored at $4^{\circ} \mathrm{C}$ for more than $1 \mathrm{~h}$. Serum was obtained by centrifugation at 3,000 rpm for $10 \mathrm{~min}$ and stored at $-80^{\circ} \mathrm{C}$ until use. Skin mucus was peeled using a cell scraper according to Staroscik and Nelson (2008). The supernatant of the mucus solution was obtained by centrifugation at 3,000 rpm for $10 \mathrm{~min}$. Serum and skin mucus samples were incubated at $45^{\circ} \mathrm{C}$ for $20 \mathrm{~min}$ before use in tests to deactivate nonspecific factors.

Equal amounts of samples from vaccinated fish col- 
lected at the same sampling point were mixed to make pooled samples. Equal amounts of all the control samples were mixed regardless of the sampling point.

\section{Serology}

Antigen preparation: A frozen stock of $V$. anguillarum (PT-213 strain) was inoculated onto tryptic soya agar containing $1.5 \% \mathrm{NaCl}(1.5 \% \mathrm{NaCl}-\mathrm{TSA})$ and incubation was carried out at $25^{\circ} \mathrm{C}$ for $18 \mathrm{~h}$. Then, a loop of the bacterial preparation was inoculated onto new 1.5\% $\mathrm{NaCl}-\mathrm{TSA}$. After incubation for $24 \mathrm{~h}$, the collected colonies were washed with PBS and centrifuged three times at 3,000 rpm for $10 \mathrm{~min}$. The bacterial pellet was resuspended in PBS and then boiled for $1 \mathrm{~h}$. L. garvieae (KG9502 strain) was prepared in the same manner except that Todd Hewitt agar (THA) was used as the growth medium.

Antibody titers against $V$. anguillarum and $L$. garvieae were measured by the agglutination method. Serum samples heated to $45^{\circ} \mathrm{C}$ for $20 \mathrm{~min}$ were diluted with a PBS dilution series from $2^{1}$ to $2^{11}$ on a 96-well plate. The same volume of antigen solution was added to the plate and incubation was carried out at $25^{\circ} \mathrm{C}$ for $1 \mathrm{~h}$. After that, the plate was incubated at $4^{\circ} \mathrm{C}$ for $18 \mathrm{~h}$. Agglutination antibody titer was determined by the highest dilution of a serum sample that caused complete clumping of each antigen.

\section{Inhibition of bacterial proliferation test}

A frozen stock of $V$. anguillarum PT-213 strain (serotype J-O-3) (National Veterinary Assay Laboratory, Tokyo, Japan) kept at $-80^{\circ} \mathrm{C}$ was thawed promptly and inoculated into tryptic soya broth containing $1.5 \% \mathrm{NaCl}$ $(1.5 \% \mathrm{NaCl}-\mathrm{TSB})$, and the whole was incubated at $25^{\circ} \mathrm{C}$ for $18 \mathrm{~h}$. After incubation, $0.1 \mathrm{~mL}$ of the medium was inoculated into $10 \mathrm{~mL}$ of new $1.5 \% \mathrm{NaCl}$-TSB. $L$. garvieae KG9502 strain (National Veterinary Assay Laboratory, Tokyo, Japan) (Kijima et al., 2007) was prepared with the same procedure as that for $V$. anguillarum except that Todd Hewitt broth (THB) was used as the growth medium.

After the second passage, an overnight culture of V. anguillarum or L. garvieae with known count was adjusted to approximately $10^{3} \mathrm{CFU} / \mathrm{mL}$ with PBS. One hundred $\mu \mathrm{L}$ of bacterial suspension was transferred to $0.5 \mathrm{~mL}$ micro-tubes and an equal volume of undiluted fish serum was added. The bacterial suspension with PBS added served as the control. The solution was mixed with a vortex mixer and kept at $25^{\circ} \mathrm{C}$. After incubation for $24 \mathrm{~h}$, bacterial count was determined by inoculating solutions prepared $\left(10^{1}\right.$ to $\left.10^{7}\right)$ onto $1.5 \%$ NaCl-TSA for $V$. anguillarum and THA for $L$. garvieae. The reduction rate of bacteria was calculated with the following formula: reduction rate $(\%)=100-\left(\log _{10} \mathrm{VS} /\right.$ $\log _{10}$ CS) $\left.\times 100\right)$. VS is the bacterial count in the tested sample obtained from vaccinated fish, and CS is the bacterial count in the tested sample obtained from control (PBS-injected) fish.

Kidney samples and total RNA isolation for microarray analysis

Kidney samples were excised from fish after blood and skin mucus sampling. Part of the kidney was immediately immersed in an RNA protecting solution, RNAlater (QIAGEN). Total RNA samples were isolated from stabilized kidney using an RNeasy-mini kit (QIAGEN) following the manufacturer's protocol and stored at $-80^{\circ} \mathrm{C}$. Then, the total RNA sample $(30 \mu \mathrm{g})$ prepared from each kidney at different time points was used for cDNA synthesis with a LabelStar Array kit, cDNA labeling module (QIAGEN). cDNAs were first labeled with aminoallyl-dUTP and purified with QIAquick spin columns (QIAquick PCR purification kit, QIAGEN). The purified cDNAs were subsequently labeled with Cy3 or Cy5 mono-functional reactive dye (GE Healthcare); RNA samples from control (PBS-injected) fish were labeled with Cy3, whereas samples from vaccinated fish were labeled with Cy5 according to the manufacturer's instructions. This was followed by purification with MinElute spin columns (LabelStar Array kit, cDNA cleanup module, QIAGEN) according to the manufacturer's instructions. Hybridization and detection of fluorescence were done following a previously reported protocol (Yasuike et al., 2007).

\section{Microarray analysis}

Microarray chips developed by Daraewiroj et al. (2008) were used to survey immune-related gene expression profiles in vaccinated fish. Microarray analysis was carried out according to the protocol reported by Daraewiroj et al. (2008). GenePix Pro 6.0 analysis software from Axon Instruments, Inc. (www.axon.com) was used to generate hybridization signals from images obtained by scanning. Feature ratio was calculated from the stimulated sample signal intensity divided by the control signal intensity. The minimum signal intensity was set at 2000. Signals lower than this level were discarded. Only the genes that exhibited feature ratios higher than 2.0 were considered as up-regulated genes (Kurobe et al., 2005).

The data were further analyzed by Cluster Program 3.0 (Clustering Library Version 1.27) using the average linkage hierarchical clustering algorithm with Euclidian distance as the similarity metric (M. De Hoon, S. Imoto, J. Nolan and S. Miyano, Open source clustering software, Bioinf Appl Note 20 (2004), pp. 1453-1454.). Cluster analysis results were visualized with TreeView (version 1.60) (A. J. Saldanha, Java Treeview extensible visualization of microarray data, Bioinformatics 20 (2004), pp. 3246-3248.). 

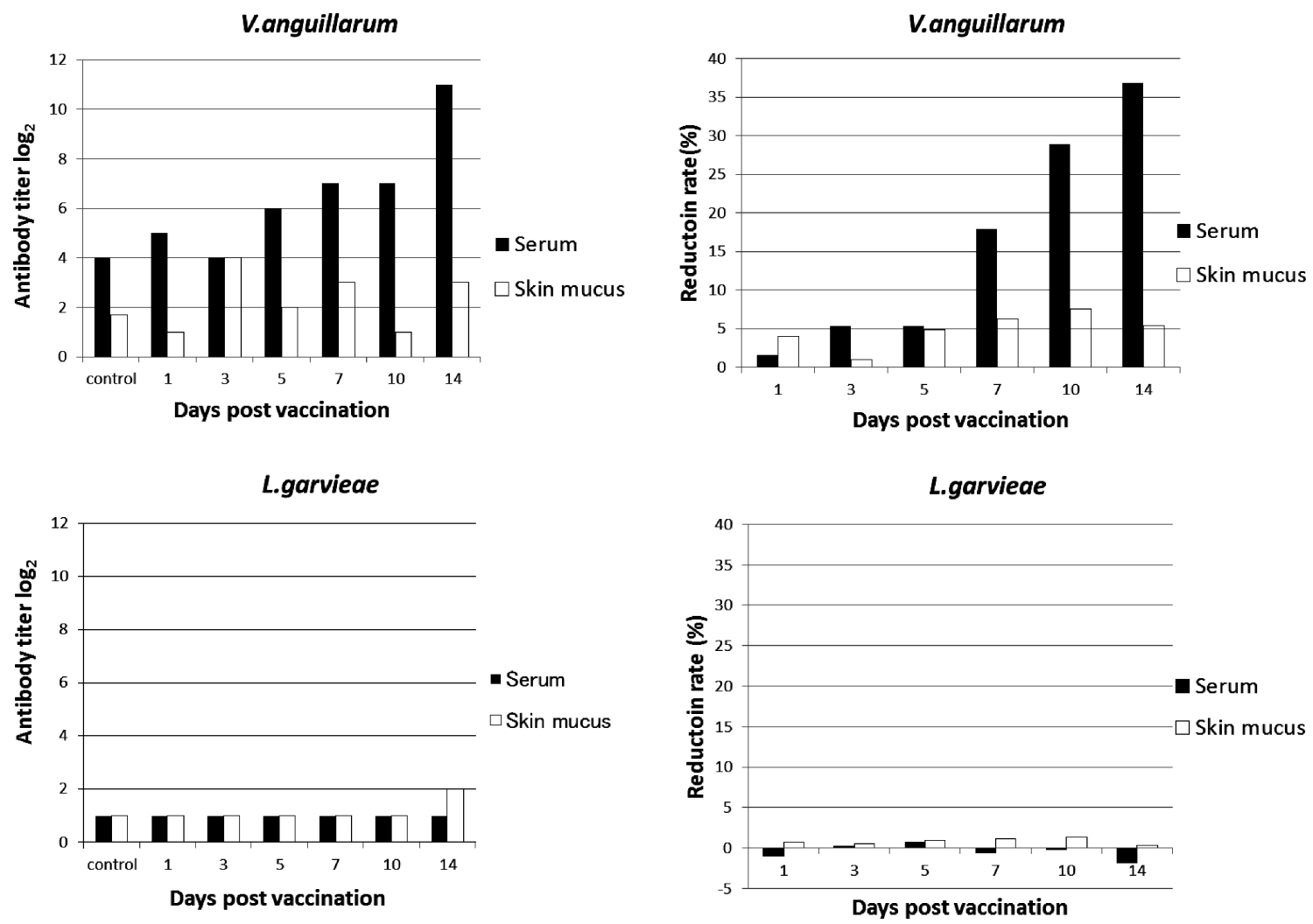

Fig. 1. Equal amounts of samples obtained on the same day and within the same group were mixed to make pooled samples. Equal amounts of all the control samples were mixed regardless of sampling point. Antibody titer (expressed as $\log _{2}$ ) against $V$. anguillarum $(A)$ and $L$. garvieae $(C)$ from vaccinated yellowtail serum or skin mucus at each sampling point $(N=5)$. Detection limit is $<2\left(2^{1}\right)$. Reduction rate (\%) of $V$. anguillarum (B) and $L$. garvieae (D) upon incubation with serum and skin mucus from vaccinated yellowtail at each sampling point $(\mathrm{N}=5)$. Reduction rate was calculated with the following formula: reduction rate $\left.(\%)=100-\left(\log _{10} \mathrm{VS} / \log _{10} \mathrm{CS}\right) \times 100\right)$. VS: Bacterial count in tested sample obtained from vaccinated fish. CS: Bacterial count in tested sample obtained from control (PBS-injected) fish.

\section{Results}

Effects of vaccination against $\mathrm{V}$. anguillarum

Serum agglutinating antibody titer in vaccinated fish showed an obvious increase at 7 and $14 \mathrm{dpv}$ (Fig. 1A). A significant correlation ( $p=0.019$ ) between reduction rate and serum agglutinating antibody titer was observed and the Pearson product-moment correlation coefficient was 0.887 (Fig. 2). In contrast, skin mucus had low antibody titer $\left(2^{1}-2^{4}\right)$ that did not show any change with the number of days post-vaccination.

The mean bacterial count on incubation with serum obtained from control fish was $4.0 \times 10^{9} \mathrm{CFU} / \mathrm{mL}$, and that with mucus was $1.4 \times 10^{10} \mathrm{CFU} / \mathrm{mL}$. The reduction rates of $V$. anguillarum due to incubation with serum from 10 and $14 \mathrm{dpv}$ fish were higher than those due to incubation with serum from 1, 3, 5, and $7 \mathrm{dpv}$ fish (Fig. 1B).

Skin mucus agglutinating antibody titer in vaccinated fish was low $\left(2^{1}-2^{4}\right)$.

Effects of vaccination against $\mathrm{L}$. garvieae

The antibody titer against $L$. garvieae was below the detection limit $\left(<2\left(2^{1}\right)\right)$ in either serum or skin mucus during the experimental period (Fig. 1C).

The reduction rate of $L$. garvieae after incubation with serum and skin mucus obtained from vaccinated fish at each sampling point is shown in Fig. 1D. There was no marked difference in the reduction rate between vaccinated samples and control samples.

\section{V. anguillarum}

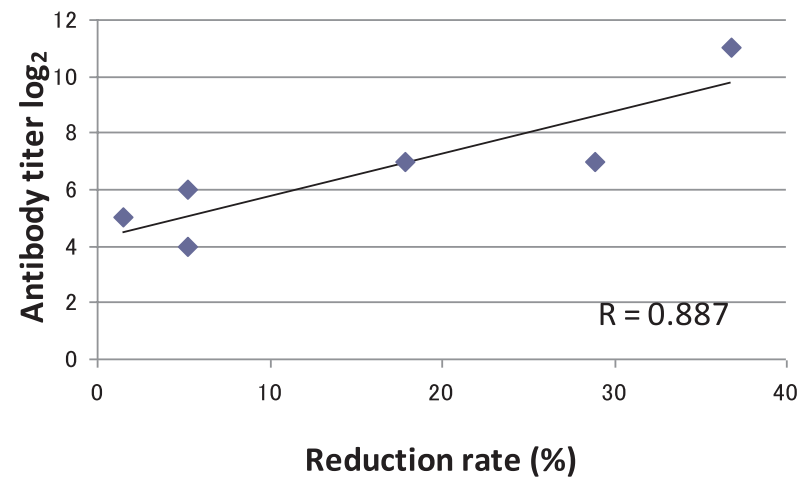

Fig. 2. Correlation between serum agglutinating antibody titer against $V$. anguillarum and reduction rate. 
Table 1. Microarray analysis of immune-related gene expression stimulated by bivalent vaccine of inactivated $V$. anguillarum and $L$. garvieae in yellowtail

\begin{tabular}{|c|c|c|c|c|c|c|c|c|}
\hline Group & Gene & $\begin{array}{c}\text { Accession } \\
\text { number }\end{array}$ & $1 \mathrm{dpv}$ & $3 \mathrm{dpv}$ & $5 \mathrm{dpv}$ & $7 \mathrm{dpv}$ & $10 \mathrm{dpv}$ & $14 \mathrm{dpv}$ \\
\hline \multirow{7}{*}{$1^{* 3}$} & CC chemokine & BB997690 & $5.2^{* 1}$ & 2.9 & N.D & 0.1 & 0.6 & N.D \\
\hline & tumor necrosis factor receptor associated factor 2 & BB997410 & N.D*2 & 2.8 & 2.0 & 0.1 & 1.1 & 0.8 \\
\hline & macrophage colony-stimulating factor receptor & BB997591 & 1.2 & 2.1 & 1.9 & 1.3 & 2.0 & 0.4 \\
\hline & LBP (LPS binding protein)/BP & BB997649 & 1.7 & 2.1 & 0.9 & 0.6 & 0.8 & 0.4 \\
\hline & colony stimulating factor 1 receptor 2 & BB997675 & N.D & 4.5 & 0.8 & 0.5 & 1.0 & N.D \\
\hline & vertebrate interferon regulatory factor family & BB996976 & 0.8 & 2.6 & N.D & 1.3 & N.D & 1.7 \\
\hline & T cell receptor gamma chain $\mathrm{V}-\mathrm{J}-\mathrm{C} 1$ & DC609801 & 0.9 & 1.5 & 3.0 & 1.4 & N.D & N.D \\
\hline \multirow{6}{*}{$2^{* 4}$} & immunoglobulin light chain & BB997721 & 1.3 & 2.7 & 3.2 & 3.3 & 1.9 & N.D \\
\hline & immunoglobulin light chain precursor & BB997682 & 1.4 & 2.4 & 2.1 & 2.2 & 1.9 & 1.3 \\
\hline & immunoglobulin heavy chain & BB997491 & 1.0 & 2.5 & 1.8 & 2.5 & 2.0 & 1.5 \\
\hline & HSP70 & BB997674 & 1.3 & 2.1 & 1.6 & 1.4 & 2.0 & 1.6 \\
\hline & MHC class II alpha antigen & BB997597 & 0.9 & 2.0 & 2.3 & 1.7 & 2.5 & 4.5 \\
\hline & neurotoxin/C59/Ly-6-like protein & BB997714 & N.D & 3.4 & 2.4 & 1.0 & 1.7 & 5.7 \\
\hline \multirow{9}{*}{$3^{* 5}$} & immunoglobulin M & BB997653 & 1.1 & 1.4 & 1.2 & 2.1 & 1.5 & 0.8 \\
\hline & tumor necrosis factor receptor superfamily. member a & BB997493 & N.D & N.D & N.D & 2.5 & 3.7 & 1.9 \\
\hline & heat shock cognate 70 & BB997492 & 1.2 & 1.8 & 1.6 & 1.4 & 2.4 & 1.9 \\
\hline & phospholipase A2-activating protein & BB997002 & 1.3 & 1.4 & 1.7 & 1.4 & 2.8 & 2.8 \\
\hline & natural killer cell enhancement factor & BB997455 & 0.6 & 1.6 & 0.6 & 1.0 & 1.4 & 2.3 \\
\hline & ferritin middle subunit; ferritin $\mathrm{M}$ & BB997379 & 0.6 & 0.7 & 0.6 & 0.8 & 1.0 & 5.6 \\
\hline & MHC class II invariant chain-like protein 2 & BB997699 & 0.5 & 1.1 & 1.0 & 1.1 & 1.2 & 2.8 \\
\hline & interleukin-18 receptor 1 precursor & BB997065 & 0.9 & 1.2 & 1.3 & 1.2 & 2.0 & 2.4 \\
\hline & Sequestosome 1 & BB997245 & N.D & 1.4 & 0.9 & 1.1 & 0.9 & 2.2 \\
\hline
\end{tabular}

${ }^{* 1}$ Values indicate fold change of gene expression at $1,3,5,7,10$, and 14 days post vaccination (dpv) with $V$. anguillarum and $L$. garvieae, compared with non-treated fish.

*2 Values not detected are indicated by N.D.

${ }^{* 3}$ Group 1 genes were up-regulated between 1 to $5 \mathrm{dpv}$.

*4 Group 2 genes were up-regulated from 1 to $14 \mathrm{dpv}$.

*5 Group 3 genes were up-regulated from 7 to $14 \mathrm{dpv}$.

\section{Changes of gene expression induced by vaccination}

Of a total of 88 immune-related genes spotted on the microarray, 22 were up-regulated (feature ratio above 2.0) after inoculating yellowtail with bivalent vaccine (Table 1). The up-regulated bio-defense genes were categorized into three groups according to their expression patterns. Group 1 genes were up-regulated between 1 to $5 \mathrm{dpv}$; Group 2 genes, from 1 to 14 dpv continuously; and Group 3 genes, from 7 to $14 \mathrm{dpv}$ (Table 1). The six up-regulated genes in Group 1 were related to non-specific cellular immunity, such as tumor necrosis factor receptor associated factor, macrophage colony-stimulating factor receptor, LBP/BP, colony stimulating factor 1 receptor 2 , and CC chemokine. Some genes belonging to Groups 2 and 3 were related to humoral immunity, including immunoglobulin heavy chain, immunoglobulin light chain, and immunoglobulin $\mathrm{M}$, whereas others were related to $\mathrm{MHC}$ class II. The up-regulated genes of immune-related proteins, such as heat shock cognate 70 , phospholipase A2-activating protein, and sequestosome, were mostly observed in Group 3.

\section{Discussion}

The immune system of yellowtail is not well understood. The objective of this study was to elucidate the immune mechanism by focusing on vaccineinduced immunity. For this purpose, the immune reactions of yellowtail following vaccination were studied.

We have shown that the serum agglutinating antibody titer against $V$. anguillarum from fish inoculated with commercial bivalent vaccine increased from $7 \mathrm{dpv}$ $\left(>128\left(2^{7}\right)\right)$ and remained significantly high at $14 \mathrm{dpv}$ $\left(>2,048\left(2^{11}\right)\right)$. In addition, serum obtained from vaccinated fish showed inhibitory effects on $V$. anguillarum proliferation, and a significant correlation between reduction rate and serum agglutinating antibody titer was observed ( $p<0.05, \mathrm{R}=0.887)$. $\quad V$. anguillarum bacterial solution incubated with serum from vaccinated fish agglutinated. High-titer serum (antibody titer of 2,048 $\left.\left(2^{11}\right)\right)$ more markedly agglutinated $V$. anguillarum than middle-titer serum (antibody titer of $256\left(2^{8}\right)$ ). In the control serum group, the agglutination of $V$. anguillarum was not observed. From these results, it can be said that antibody plays an important role in vaccine-induced 
immunity. Our findings corroborate those of other studies (Thelma and White, 1972; Thuvaner et al., 1987) in which antibody production is induced by vaccination.

L. garvieae is serologically divided into two types, $\mathrm{KG}-$ and $\mathrm{KG}+$ phenotypes. However, the biochemical characteristics of the two phenotypes are identical and it has been reported that rabbit anti KG- serum agglutinates both KG+ and KG- serotypes (Kitao, 1982; Hirono et al., 1999; Ooyama et al., 1999). KG- serotype isolates are more virulent than $\mathrm{KG}+$ serotype isolates due to the presence of a capsule (Ooyama et al., 2002) that makes them resistant to opsonophagocytosis and host serum killing (Yoshida et al., 1996, 1997). All vaccine strains have the $\mathrm{KG}$ - phenotype and the $\mathrm{KG}-$ strain (KG 9502) is used as the standard strains in the challenge test. Yoshida et al. (1996) reported that yellowtail vaccinated with the KG- phenotype could not produce high agglutination titer against $\mathrm{KG}-$, but could promote phagocytosis of KG- phenotype. Complement may play an important role in immunity against $L$. garvieae. Our results corroborate the above findings: we did not observe any increase of the antibody titer against KG- phenotype L. garvieae or any inhibition of pathogen induced by complement-inactivated serum from vaccinated fish. These results suggest that the prophylactic effects of commercial vaccine on $L$. garvieae are not induced by KG- antibody production. Therefore, it is difficult to evaluate vaccine efficacy against lactococcosis by measuring KG- antibody titer and a more suitable marker for evaluating vaccine efficacy is desired

To determine other immune responses induced by vaccination, we conducted microarray analysis to profile immune-related gene expression. Only immunerelated genes that were up-regulated by vaccination were analyzed in this study. Microarray analysis revealed that 22 immune-related genes showed upregulation after vaccination. Group 1 consists of innate immune-related genes that are related to macrophage stimulation and inflammation. Immunoglobulin heavy chain $(\operatorname{lgH})$, which is thought to be the major transmembrane receptor on the surface of $B$ cells in all teleost species (Wilson et al., 1990), and its related genes were categorized in Group 2 in this study. Two immunoglobulin light chain related genes were also included in Group 2. The up-regulation of MHC class II alpha antigen (Group 2) and MHC class II invariant chain-like protein 2 (Group 3) possibly indicates that CD4+ $T$ cells respond to vaccine antigen. Those results suggest that innate immunity is first stimulated by the vaccination and then humoral immunity is stimulated. The vaccine used in this study contained both Gram-negative V. anguillarum and Gram-positive L. garvieae. LPS is one of the major antigens of Gram-negative bacteria and known to induce T-cellindependent type I immune response. T-cell-independ- ent antigens can activate B cells directly through the Toll-like receptor (Fagarasan and Honjo, 2000). The current study shows that T-cell-independent type II antigens, such as polysaccharides, can induce the production of memory B cells (Obukhanych and Nussenzweig, 2006). These findings suggest that $T$ cell is not always needed for the production of specific antibodies for some antigens. The present experiment demonstrated the up-regulation of $\mathrm{T}$ cell receptor gamma chain V-J-C1 (Group 1), MHC class II alpha antigen (Group 2), and MHC class II invariant chain-like protein 2 (Group 3). All these are indicative of $\mathrm{T}$ cell activation, but are not sufficient to determine which antigen induced the T-cell-dependent immune response.

Skin mucus had low antibody titer against $V$. anguillarum. As the first defense against infection, mucus contains several antibacterial factors (Alexander and Ingram, 1992; Rombout et al., 1993; Aranishi and Nakane, 1997). IgM is one of those. Our results are not sufficient to determine whether an antibody is a specific one or a natural one. Nevertheless, they suggest that mucus contains some antibodies against pathogens.

The HSP 70 related genes were categorized in Groups 2 and 3 . HSP 70 is a kind of stress protein present in all cells. It serves as a molecular chaperone in the cell death mechanism (Garrido et al., 2001) and is an extracellular protein with regulatory effects on human monocytes, playing a dual role as a chaperone and a cytokine (Asea et al., 2000). HSP 70 may be up-regulated by vaccination as it induced by stress and inflammation. Other proteins related to cell defense were also up-regulated, such as neurotoxin/C59/Ly-6like protein (Group 2), phospholipase A2-activating protein (Group 3), and sequestosome 1: P62 protein (Group 3). These also show immune stimulation by vaccine. The IL-18 receptor 1 precursor related gene, which is a kind of cytokine that stimulates both Th1 and Th2 responses, was categorized in Group 3 (Nakanishi et al., 2001) and its expression is increased by LPS (Abu et al., 2008). It is suggested that the up-regulation of this gene is likely induced by vaccination. Microarray analysis suggested that both innate immunity and humoral immunity are stimulated by vaccination. However, the results are due to the use of the bivalent vaccine, and further studies of genes up-regulated by vaccination are needed.

In conclusion, this is the first report of a large-scale immune-related gene expression profiling in vaccinated yellowtail using microarray analysis. Vaccination elicited immune response in yellowtail, activating both nonspecific cellular immunity and humoral immunity. We also conducted RT-PCR of some genes to confirm the microarray results (data not shown). The signal intensity scores from the microarray analysis corresponded to the RT-PCR results, suggesting that the gene expres- 
sion pattern on the microarray was reliable. Immune response to both antigens, $V$. anguillarum and $L$. garvieae, was observed in this study. Yellowtail may use a different type of immune system for different pathogens. Our results suggest that a specific antibody plays an important role in vibriosis. On the other hand, there was no evidence of acquired immunity to lactococcosis. To determine how yellowtail acquires immunity to L. garvieae, further studies of the immune response induced by lactococcosis vaccination are needed.

\section{Acknowledgments}

The authors acknowledge Professors Takashi Aoki and Ikuo Hirono of the Laboratory of Genome Science, Tokyo University of Marine Science and Technology, for providing microarray chips and their kind technical support in the microarray analysis.

\section{References}

Abu, E. M., E. Lunenfeld and M. Huleihel (2008): LPS increases the expression levels of IL-18, ICE and IL-18 R in mouse testes. Am. J. Reprod. Immunol., 60, 361-371.

Alexander, J. B. and G. A. Ingram (1992): Noncellular nonspecific defence mechanisms of fish. Annu. Rev. Fish Dis., 2, 249-279.

Aranishi, F. and M. Nakane (1997): Epidemal proteases of the Japanese eel. Fish Physiol. Biochem., 16, 471-478.

Asea, A., S. K. Kraeft, E. A. Kurt-Jones, M. A. Stevenson, L. B. Chen, R. W. Finberg, G. C. Koo and S. K. Calderwood (2000): HSP70 stimulates cytokine production through a CD14-dependant pathway, demonstrating its dual role as a chaperone and cytokine. Nature Medicine, 6, 435-442.

Bengtén, E., S. Strömberg and L. Pilström (1994): Immunoglobulin VH regions in Atlantic cod (Gadus morhua L.): Their diversity and relationship to $\mathrm{VH}$ families from other species. Comp. Immunol., 15, 143-152.

Caipang, C. M. A., N. Hynesa, J. Puangkaew, M. F. Brinchmann and V. Kiron (2008): Intraperitoneal vaccination of Atlantic cod, Gadus morhua with heat-killed Listonella anguillarum enhances serum antibacterial activity and expression of immune response genes. Fish Shelfish Immunol., 24, 314-322.

Caipang, C. M. A., F. Brinchmanna and V. Kiron (2009): Profiling gene expression in the spleen of Atlantic cod, Gadus morhua, upon vaccination with Vibrio anguillarum antigen. CBP Part B., 153, 261-267.

Daraewiroj, D., H. Kondo, I. Hirono and T. Aoki (2008): Immunerelated gene expression profiling of yellowtail (Seriola quinqueradiata) kidney cells stimulated with ConA and LPS using microarray analysis. Fish Shellfish Immunol., 24, 260-266.

Ellis, A. E. (2001): Innate host defence mechanisum of fish against viruses and bacteria. Dev. Comp. Immunol., 25, 827-839.

Espelid, S., O. M. Rødseth and T. O. Jørgensen (1991): Vaccination experiments and studies of the humoral immune responses in cod, Gadus morhua L., to four strains of monoclonal-defined Vibrio anguillarum. J. Fish Dis., 14, 185-197.
Fagarasan, S. and T. Honjo (2000): T-independent immune response: New aspects of B cell biology. Science, $\mathbf{2 9 0}$ 88-92.

Fasta, M. D., D. E. Sims, J. F. Burka, A. Mustafa and N. W. Ross (2002): Skin morphology and humoral non-specific defence parameters of mucus and plasma in rainbow trout, coho and Atlantic salmon. Comp. Biochem. Physiol., 132, 645-657.

Garrido, C., S. Gurbuxani, L. Ravagnan and G. Kroemer (2001): Heat shock proteins: Endogenous modulators of apoptotic cell death. BBRC, 286, 433-442.

Grøntvedt, R. N. and E. Sigrun (2004): Vaccination and immune responses against a typical Aeromonas salmonicida in spotted wolffish (Anarhichas minor Olafsen). Fish Shellfish Immunol., 16, 271-285.

Hasting, T. S. and A. E. Ellis (1990): Detection of antibodies induced in rainbow trout by different Aeromonas salmonicida vccine preparations. J. Aquat. Anim. Health, 2, $135-140$.

Hirono, I., H. Yamasita, C. I. Park, T. Yosida and T. Aoki (1999): Identification of genes in a KG- phenotype of Lactococcus garvieae, a fish pathogenic bacterium, whose proteins react with anti KG- rabbit serum. Microb. Pathog., 27, 407-417.

Hjelmeland, K., M. Christie and J. Raa (1983): Skin mucus protease from rainbow trout, Salmo gairdneri Richardson, and its biological significance. J. Fish Biol., 23, 13-22.

lida, T., T. Wakabayashi and S. Egusa (1982): Vaccination for control of streptococcal disease in cultured yellowtail. Fish Pathology, 16, 201-206.

Ingilæ, M., J. A. Arnesen, V. Lund and G. Eggset (2000): Vaccination of Atlantic halibut Hippoglossus hippoglossus L., and spotted wolffish Anarhichas minor L., against atypical Aeromonas salmonicida. Aquaculture, 183, 31-44.

Kijima, M., M. Kawanishi, T. Yoshida, M. Asagi, K. Kawano, T. Honma, S. Hoshi, S. Manabe, Y. Kimura, M. Kuwahara, K. Yagyu and S. Suzuki (2007): A study conducted to standardize testing of the efficacy of inactivated lactococcus vaccines. Annu. Rep. NVAL, 44, 39-47.

Kitao, T. (1982): The methods for detection of Streptococcus sp. Causative bacteria of streptococal disease of cultured yellowtail, Seriola quinqueradiata, especially, their cultural, biochemical and serological properties. Fish Pathol., 17, 17-26.

Kurobe, T., M. Yasuike, T. Kimura, I. Hirono and T. Aoki (2005): Expression profiling of immune-related genes from Japanese flounder Paralichthys olivaceus kidney cells using cDNA microarrays. Dev. Comp. Immunol., 29, 515-523.

Kwon, S. R., T. Nishizawa, I. Takami and M. Yoshimizu (2010): Antibody detection against red sea bream iridovirus (RSIV) in yellowtail Seriola quinqueradiata using ELISA. Fish Pathol., 45, 73-76.

Nakanishi, K., T. Yoshimoto, H. Tsutsui and H. Okamura (2001): Interleukin-18 is a unique cytokine that stimulates both Th1 and Th2 responses depending on its cytokine milieu. Cytokine \& Growth Factor Reviews, 12, 53-72.

Obukhanych, T. V. and M. C. Nussenzweig (2006): T-independent type II immune responses generate memory $B$ cells. J. Exp. Med., 203, 305-310.

Ooyama, T., A. Kera, T. Okada, V. Inglis and T. Yoshida (1999): The protective immune response of yellowtail Seriola quinquwradiata to the bacterial fish pathogen Lactococcus garvieae. Dis. Aqua. Org., 37, 121-126.

Ooyama, T., Y. Hirokawa, T. Minami, H. Yasude, T. Nakai, M. Endo, L. Ruangpan and T. Yoshida (2002): Cell- surface properties of Lactococcus garvieae strains and their 
immunogenicity in the yellowtail Seriola quinqueradiata. Dis. Aqua. Org., 51, 169-177.

Pilström, L. and A. Petersson (1991): Isolation and partial characterization of immunoglobulin from cod (Gadus morhua L.). Dev. Comp. Immunol., 15, 143-152.

Rombout, J. H. W. M., N. Tavernea, M. V. D. Kamp and A. J. Taverne-Thielea (1993): Differences in mucus and serum immunoglobulin of carp (Cyprinus carpio L.). Dev. Comp. Immunol., 17, 309-317.

Steine, N. O., G. O. Melingen and H. I. Wergeland (2001): Antibodies against Vibrio salmonicida lipopolysaccharide (LPS) and whole bacteria in sera from Atlantic salmon (Salmo salar L.) vaccinated during the smolting and early post-smolt period. Fish Shellfish Immunol., 11, 39-52.

Stenvik, S., A. S. Lundbäck, T. Ø. J. Ørgensen and L. Pilström (2000): Variable region diversity of the Atlantic cod (Gadus morhua L.) immunoglobulin heavy chain. Immunogenetics, 51, 670-680.

Schrøder, M. B., S. Espelid and T. Ø. Jørgensen (1992): Two serotypes of Vibrio salmonicida isolated from diseased cod (Gadus morhua L.) virulence, immunological studies and vaccination experiments. Fish Shelfish Immunol., 2, 211-221.

Staroscik, A. M. and D. R. Nelson (2008): The influence of salmon surface mucus on the growth of Flabovacterium columnare. J. Fish. Dis., 31, 59-69.

Thelma, C. F. and A. White (1972): Antibody production in the plaice (Pleuronectes platessa L.) after oral and parenteral immunization with Vibrio anguillarum antigens. Aquaculture, 1, 417-428.
Thuvaner, A., T. Thongslo, E. Jansson and B. Sundquist (1987): Duration of protective immunity and antibody titre mesured by ELISA after vaccination of rainbow trout, Salmo gairdneri Richardson, against vibriosis. J. Fish. Dis., 10, 479-786.

Wilson, M. R., A. Marcuz, F. V. Ginkel, N. W. Miller, L. W. Clem, D. Middleton and G. W. Warr (1990): The immunoglobulin $M$ heavy chain constant region gene of the channel catfish, Ictalurus punctatus: an unusual mRNA splice pattern produces the membrane from of the molecule. Nucleic Acids. Res., 18, 5277-5233.

Yasuike, M., H. Konodo, I. Hirono and T. Aoki (2007): Difference in Japanese flounder, Paralichthys olivaceus, gene expression profile following hirame rhabdovirus (HIRRV) $\mathrm{G}$ and $\mathrm{N}$ protein DNA vaccination. Fish Shelfish Immunol., 23, 531-541.

Yoshida, T., T. Eshima, Y. Wada, Y. Yamada, E. Kakizaki, M, Sakai, T. Kitao and V. Inglis (1996): Phenotypic variation associated with an anti-phagocytic factor in the bacterial fish pathogen Enterococcus seriolicida. Dis. Aqua. Org., 25, 81-86.

Yoshida, T., M. Endo, M, Sakai and V. Inglis (1997): A cell capsule with possible involvement in resistance to opsonophagocytosis in Enterococcus seriolicida isolated from yellowtail Seriola quinqueradiata. Dis. Aqua. Org., 29, 233-235.

Zaccone, R. and M. Mancuso (2008): First report on antibody respose of Seriola dumerilii (Rossp 1810) challenged with Listonella anguillarum. Fish Shelfish Immunol., 25, 689-692. 